\title{
Bad Art and Good Taste
}

\author{
Per Algander ${ }^{1}[0$
}

Published online: 19 September 2018

(c) The Author(s) 2018

Aesthetic value and good taste usually go hand in hand. A person with good taste is, typically, someone who appreciates things which exhibit some aesthetic quality or excellence. However, in ordinary life it is commonplace that we indulge in things which are lacking in aesthetic value. For example, we might prefer to watch Days of Our Lives rather than The Wire, or to read a bad crime novel rather than good poetry.

It is tempting to draw the conclusion that we are making a mistake, and lacking good taste, when our aesthetic attitudes do not match up against the aesthetic value of the things we prefer. However, this conclusion may be too quick. It has recently been argued by John Dyck and Matt Johnson ${ }^{1}$ that appreciating bad art—art which lack aesthetically good making features or whose bad making features clearly outweigh its good making ones-isn't always inappropriate. In this paper I will argue that while there might be a case to be made for this claim, the problem which Dyck and Johnson identify is much more general and that their proposed solution can at best be a partial one.

\section{The Problem of Bad Art}

In their paper "Appreciating Bad Art," Dyck and Johnson discuss the puzzling cases of art where some commentators have expressed the view that the work in question is "so bad that it is good." Examples of such works mentioned by Dyck and Johnson include Ed Wood's Plan 9 From Outer Space, Wiseau's The Room and the exhibits at The Museum of Bad Art in Boston. In all of these examples the work in question is clearly aesthetically flawed. However, the puzzling claim is that it is this very fact which some commentators have held to be what makes them aesthetically good.

\footnotetext{
1 John Dyck and Matt Johnson, “Appreciating Bad Art," The Journal of Value Inquiry, 51 (2017): 279292.

${ }^{2}$ Ibid., pp. 279-280.
}

Per Algander

per.algander@filosofi.uu.se

1 Uppsala Universitet, Filosofiska institutionen, Box 627, 75126 Uppsala, Sweden 
The problem is not whether a work of art can be aesthetically good in one way but bad in another. Such examples are common and not very puzzling. For example, a film can have very bad acting but a very good plot. Dyck and Johnson also note that the problem is not about whether a work can exemplify different values, as in the case of a morally bad book which is nevertheless aesthetically good. The claim, rather, concerns the aesthetic and whether Plan 9, for example, is aesthetically good because of its aesthetic flaws. Finally, the claim is not how a bad work can be aesthetically good all things considered. The claim should rather be understood as a claim about bad works being good to an extent, or pro tanto: Plan 9 is aesthetically good to an extent, not all things considered, because it is so bad.

Dyck and Johnson formulate two challenges for the view that some works of art are good because they are bad. The first problem is to make sense of the claim that a thing can be good because it is bad. How can this be?

The second problem concerns aesthetic value and correct appreciation. Dyck and Johnson claim that correct appreciation is a favorable response to an objects good qualities, to the extent that the object warrants appreciation. ${ }^{3}$ The problem is that if bad art lacks good qualities then it can never be correct to appreciate it.

Dyck and Johnson set out to solve both problems. That is, they aim to show how a thing can be "good because it is bad" and how it can be correct to appreciate such things.

\section{Bad Art and the Bizarre}

Dyck and Johnson suggest that both problems can be solved by appealing to the bizarreness of bad art. They claim that

The artistic failure in these works is an artistic vice, but an aesthetic merit; these works are aesthetically good because they are artistically bad. On our account, artistic failure can produce an aesthetically positive effect of bizarreness. $^{4}$

On their view, an artwork is artistically bad when the intentions of the author fail in a certain way. For example, a novel which is intended by its author to be a thoughtful reflection on the horrors of war, but which is actually a glorification of war, would be an artistic failure even if the novel is otherwise well written. ${ }^{5}$

\footnotetext{
3 “Appreciation is a favorable response to an object's (or person's, or event's) good qualities, to the extent that the object (or person, or event) warrants a favorable response" (ibid., pp. 280-281). I assume that they intend this to be a gloss of correct appreciation, since it seems widely counter intuitive to hold that a person who favours something which doesn't warrant a favourable response is not in fact appreciating that thing.

4 Ibid., p. 281.

5 Dyck and Johnson do not elaborate further on what makes an artwork artistically good. However, what they say about artistic value is consonant with views of artistic value where the artistic value of a work is closely connected to the achievement of the artist. For a sketch of such a view, see Andrew Huddleston, "In Defense of Artistic Value," The Philosophical Quarterly, 62 (2012): 705-714.
} 
In the case of many works which are "so bad that it is good" it seems plausible to hold that they are artistic failures. Plan 9 is an artistic failure because Ed Wood's intention, or ambition, to create an exciting and thrilling sci-fi film is an absolute failure. Dyck and Johnson's claim is that this mis-match between the author's intention and the actual result makes the film bizarre. Being bizarre is, furthermore, an aesthetically good making feature according to Dyck and Johnson. Hence, Plan 9 is artistically bad but aesthetically good, at least to some extent.

Armed with this view Dyck and Johnson can reply to the two problems they set out to solve. First, how can a work of art be good because it is bad? In reply, Dyck and Johnson can claim that this only seems paradoxical because we haven't distinguished between artistic and aesthetic value. Plan 9 and The Room are aesthetically good because they are artistically bad, thus dispelling the air of contradiction. Second, how can it be correct to appreciate a work such as Plan 9? Dyck and Johnson can reply that Plan 9 is aesthetically good in one way-it is bizarre-and hence it is correct to appreciate it to that extent.

It is worth noting that the way in which Dyck and Johnson solve the first problem is by distinguishing between two kinds of value: aesthetic and artistic. Though it seems as if some art works are "so bad that they are good," this is in fact not really true on their view, at least not if "bad" and "good" are read as referring to the same kind of value. On their view, rather, some works are so bad in one way (artistically) that they are good in another way (aesthetically). Their solution is therefore structurally similar to possible solutions mentioned above, where the value of aesthetically bad art is located in its moral or cognitive value.

In the remainder of this section I will argue that Dyck and Johnson's solution to the first problem (how can something be so bad that it is good?) faces two problems. First, it is unclear what their view of the good making property of bad art actually is. Second, independently of how Dyck and Johnson's view is further clarified, there are reasons to doubt that they identify a good making feature of bad artworks.

According to Dyck and Johnson, the aesthetically good making feature of bad art is that such works can be bizarre. The bizarreness, in turn, is a property a work has in virtue of a mis-match between the author's intention and the actual result. However, they go on to claim that there is a further relevant difference between cases where bizarreness is intentional and and when it is unintentional:

When bizarreness is intentional, as in the works of David Lynch, there is at least the order of the underlying intention for bizarreness; audiences know that there is some intentional force creating the bizarreness at bottom. But when bizarreness occurs unintentionally, there is a unique effect. The lack of a bottom-level intention exacerbates our sense of bewilderment - it exacerbates the weirdness of the piece. It is this particular feature that, we think, is unique to good-bad art. ${ }^{6}$

\footnotetext{
${ }^{6}$ Dyck and Johnson, op.cit., pp. 284-285.
} 
However, the comparison with Lynch does not seem very apt. First, in Lynch's films there is no mis-match between authorial intent and aesthetic quality which Dyck and Johnson take to be characteristic of bad art. It is therefore unclear why Lynch's films exemplify the same property-bizarreness-as some bad art.

The difference between bad art and Lynch's films illustrates the importance of distinguishing, on the one hand, between the property of being bizarre and that in virtue of which a work is bizarre. In the case of bad art it might be plausible that such works are bizarre because there is a mis-match between the author's intent and the actual result, but in the case of Lynch the bizarreness must be had in virtue of something else; perhaps in virtue of the disordered content of the work.

It therefore seems that the view proposed by Dyck and Johnson requires some further clarification. In response to the remarks above, Dyck and Johnson could claim that bizarreness is an aesthetically good making feature but that this feature can be realized in different ways. A possible view of bizarreness, which is congenial with some of their remarks, is that bizarreness is the dispositional property of tending to produce a certain kind of bewilderment. For example, Dyck and Johnson quote Charles Timmer's view that bizarreness "defies precise definition. However, it is possible to mention one inherent quality:- its irrelevancy, and one typical effect:-its capability of producing bewilderment."7

It seems plausible that this dispositional property can be had in virtue of an artwork's content (as in the case of Lynch's films) or its relation to the author's intent (as in the case of Plan 9). This view therefore allows for the possibility that there are different ways in which a work can be bizarre, yet still identifying a common good making feature (the tendency to produce a certain kind of experience) across works such as Plan 9 and Lynch's Mulholland Drive. Dyck and Johnson could argue that the bewildering effect can be pleasing, or enjoyable, thereby putting bizarreness on a par with other aesthetically good making features such as beauty.

However, it seems strained, to say the least, to say that Plan 9 and Mulholland Drive share some aesthetically good making features. An alternative view of what makes Plan 9 aesthetically good, and which differentiates it from Mullholland Drive, is to say that it is the conspicous discrepancy between authorial intention and the actual result which is the aesthetically good making feature, regardless of whether this makes the work bizarre or not.

A term for the feature which this view identifies as the good making feature could be "absurd." Thomas Nagel describes the absurd as "a situation is absurd when it includes a conspicous discrepancy between pretention or aspiration and reality." 8 We can, given this view, easily see how absurdity can arise in the case of bad art. In the case of bad art there is a conflict, or lack of coherence, between a work's aesthetic and artistic qualities and therefore a conspicous discrepance between pretention or aspiration (the author's intention) and reality.

\footnotetext{
7 Dyck and Johnson, op.cit., p. 284.

8 Thomas Nagel, "The Absurd," in Mortal Questions. (Cambridge: Cambridge University Press, 1979), p. 13.
} 
It is therefore unclear what the good making feature of bad art-if indeed there is one-actually is. However, reflecting on instances of bad art and other works which are bizarre reveal a further difficulty for Dyck and Johnson's claim that bizarreness is a good making feature in the case of bad art.

Why would a tendency to produce bewilderment, or a discrepancy between the author's intent and the actual result make an artwork better?

If we consider first the view that it is the discrepancy which is the aesthetically good making feature, it doesn't seem to be the case that this is an aesthetically good making feature in other contexts. If human existence is absurd, as it may well be, then this is hardly a good making feature of our lives. Furthermore, if it is the discrepancy between authorial intent and the actual result which makes a work bizarre, and therefore aesthetically good to an extent, then we should expect a work with low (perhaps no) artistic value but great aesthetic value to also be bizarre. However, this does not seem to be the case. A computer selecting colours and shapes at random could produce a very beautiful object but it would plausibly lack artistic value. It does not seem plausible that in addition to its aesthetic value which derives from its beauty, this object is also aesthetically good because of the discrepancy between its artistic and aesthetic value.

The view that it is the tendency to produce bewilderment which is the good making feature might be more plausible. After all, the experience Dyck and Johnson allude to can be described as pleasing, in a way, and it would therefore seem to be similar to other clear examples of aesthetically good making features, such as beauty.

Dyck and Johnson also acknowledge that not all instances of bizarreness are aesthetically good making. They mention a job interview, a conversation, and a wedding as situations where being bizarre isn't always a good thing. They also claim that not all bizarreness in art is good making, for example in the case of a bizarre dialogue or character. ${ }^{9}$

However, these concessions to the limitations of bizarreness as a good making property are not sufficient to make the view plausible. The problem for their view is that it is not sensitive to different ways in which a work of art can produce bewilderment. What is striking about Lynch's films is that it is the content of these films which is disordered and which makes the film bizarre. Bad art, on the other hand, need not have a disordered or incoherent content. In the case of bad art it seems to be the work, not the content, which has the property which Dyck and Johnson are after. Lynch's films on the other hand are bizarre because they portray bizarreness while the instances of bad art which Dyck and Johnson discuss do not portray bizarreness.

The difference between a work being bizarre in virtue of its content and in virtue of other aspects can be illustrated by making a distinction between portrayed bizarreness and merely exemplified bizarreness. Portraying bizarreness, as well as

\footnotetext{
9 See Dyck and Johnson, op.cit, p. 285. Note that regarding their examples of bizarre situations it seems plausible that there are other values at stake which affect our intuitions about them. For example, it is not prudentially good to be bizarre at a job interview.
} 
portraying absurdity, seems to be a plausible candidate for an aesthetically good making feature; works such as Kafka's novels and Lynch's films support this contention. Merely exemplifying absurdity or bizarreness typically isn't an aesthetically good making feature, regardless of whether it is exemplified by a work of art or not. ${ }^{10}$

The point can be further illustrated by considering other properties, such as 'tragic'. Many great works of art portray tragedy, and in some cases it is this portrayal of tragedy which contributes to them being great. In such cases it is the content of the work which makes it appropriate to say that the work is tragic. However, when the work itself is tragic, perhaps because of the role it played in the author's life, then we would not say that this property is what makes the work aesthetically good.

One way for Dyck and Johnson to support their view would be to consider uncontroversial cases where a work of art is aesthetically good because it is bizarre (i.e, it tends to produce bewilderment). However, typical cases of art which is aesthetically good because it is bizarre are cases where the work is bizarre in virtue of its content and not in virtue of the relation between content and the creator's intention. Supporting Dyck and Johnson's contention that bad art exemplifies an aesthetically good making property because a tendency to produce bewilderment in general is a good making feature might therefore be difficult.

In light of the distinction between a work of art and its content a slightly modified view might be plausible however. On this view, tending to produce bewilderment is only a good making feature when the tendency is had in virtue of the content of the work. Consider, for example, a painting which tends to produce bewilderment in onlookers because the paint used has a hallucinogenic effect similar to bewilderment. In this case it does not seem plausible to say that the work is aesthetically good partly in virtue of its being bizarre, even though the work tends to produce bewilderment in onlookers. In order for the work to be aesthetically good because it is bizarre it seem plausible to require that the tendency to produce bewilderment is grounded in the work's content, and not some other aspect of the work.

This modified view will be of little help to Dyck and Johnson however, since bad art typically exemplify, and does not portray, absurdity or bizarreness. On this view bad art would not be good in virtue of being bizarre, and hence we would still be lacking an explanation of the first problem Dyck and Johnson set out to solve.

\footnotetext{
$\overline{10}$ I do not intend the distinction between properties of an artwork and properties portrayed, or represented, by an artwork, to invovle a commitment to aesthetic formalism. Formalism might arrive at a similar conclusion as I am arguing for. However, I am relying on the weaker claim that there seems to be an aesthetic difference between portraying bizarreness and exemplifying it. See Nick Zangwill, "In Defence of Moderate Aesthetic Formalism," The Philosophical Quarterly, 50 (2000): 476-493.
} 


\section{Bad Art and Good Taste}

So far I have raised some doubts regarding Dyck and Johnson's solution to the first problem; namley, how can a work of art be good because it is bad? I will now turn to the second problem which they seek to address. I will argue that the problem is more general than they acknowledge, and that their solution can at best be a partial solution to the more general problem.

The second problem Dyck and Johnson set out to solve concernes aesthetic value and appreciation. Can it be warranted to appreciate something which lacks aesthetically good features? Dyck and Johnson assume that there is a connection between aesthetic value and appreciation: valuable things typically call for a response of some kind. In the case of aesthetic value, a plausible view is that the response in question is appreciation. However, bad works of art seem to lack aesthetically good making features. It therefore seems to follow that it cannot be correct to appreciate bad art. However, there also seems to be aesthetically sensible people who appreciate bad art. ${ }^{11}$ If it cannot be correct to appreciate bad art, then these people would be making an obvious mistake, but this seems unlikely since they are otherwise aesthetically sensible.

Two clarificatory remarks regarding appreciation before proceeding. First, the kind of attitude which aesthetic value calls for might be different from the kind of attitude which other values call for. That is, there might be something distinct about aesthetic appreciation compared to, say, the kind of attitudes which moral values call for. For example, the pro attitude a morally conscientious person has towards a generous act is different from the attitude an aesthetically sensible person has towards a great work of art. Second, the kind of appreciation which aesthetic value calls for is usually thought to be non-instrumental. What distinguishes aesthetic appreciation from some (though not all) other kinds of pro attitudes is that to aesthetically appreciate a thing is to have the right kind of attitude toward that object for its own sake. Appreciating a work of art because it can be sold for a profit, for example, is not to appreciate it for its own sake.

The idea that there is a close relation between correct appreciation and intrinsic aesthetic value is consonant with traditional views of aesthetic value. For example, according to the (neo-) Humean view the verdicts of the ideal critic-a person with perfect understanding of, and responsiveness to, art-is a reliable indicator of intrinsic aesthetic value and serves as the standard by which to judge actual person's aesthetic attitudes. ${ }^{12}$

With these clarificatory remarks, the relation between correct appreciation and aesthetic value which is relevant to the second problem might be the following:

\footnotetext{
11 Dyck and Johnson, op.cit, pp. 279-80.

12 See Jerrold Levinson, "Artistic Worth and Personal Taste." The Journal of Aesthetics and Art Criticism, 68 (2010): 225-233 and Levinson, "Hume's Standard of Taste: The Real Problem." The Journal of Aesthetics and Art Criticism, 60 (2002): 227-238 for a presentation and defence of this view.
} 
The Appreciation Requirement: It is permissible to aesthetically appreciate $x$ for its own sake iff $x$ is intrinsically aesthetically good to some extent. ${ }^{13}$

An alternative version of the requirement would be to hold that appreciation for intrinsically aesthetically good things is not only permissible but required. However, this view would have the implausible result that not appreciating something intrinsically aesthetically good is impermissible, even if the object is an artefact of some distant civilization which one will never come into contact with. The less demanding formulation in terms of permission is therefore preferable.

The Appreciation Requirement is central to the second problem which Dyck and Johnson seek to solve. The problem, or perhaps puzzle, is to explain how it can be correct to appreciate bad art given the Appreciation Requirement. Dyck and Johnson's solution to the puzzle, as we have seen, is to claim that bad art can exemplify an aesthetically good making property-bizarreness-and it is therefore not inconsistent to say that it can be correct to appreciate bad art.

However, the Appreciation Requirement does not seem to be the whole story about how aesthetic values and aesthetic attitudes are related. For example, it seems plausible that correct appreciation is sensitive to degrees of aesthetic value. Dyck and Johnson seem to agree on this since they hold that correct appreciation is a favorable response to an objects good qualities, to the extent that the object warrants appreciation. ${ }^{14}$ To account for degrees of aesthetic value it might be tempting to endorse the following as a natural extension of the Appreciation Requirement:

The Preference Requirement: It is permissible to aesthetically prefer $x$ to $y$ iff $x$ is intrinsically aesthetically better than $y .{ }^{15}$

The term aesthetically prefer is intended to be a term of art which designates the comparative of appreciate. We might say, for example, that an agent $(A)$ aesthetically prefers $x$ to $y$ iff $A$ aesthetically appreciates $x$ more than $A$ aesthetically appreciates $y$. In what follows, I will occasionally omit the qualifier "aesthetically" from "aesthetically prefer" for brevity.

Note that the Preference Requirement need not be very demanding since it seems plausible that there is widespread incomparability and indeterminacy among aesthetically valuable objects. However, for objects where a determinate value relation holds, the requirement seems plausible, at least in so far as we find the original Appreciation Requirement plausible.

\footnotetext{
13 The Appreciation Requirement is strikingly similar to buck passing and fitting attitude analyses of value. See Wlodek Rabinowicz and Toni Rønnow-Rasmussen, "Strike of the Demon: On Fitting ProAttitudes and Value." Ethics 114 (2004): 391-423. However, I do not mean to suggest that the Appreciation Requirement is an analysis of aesthetic value, but merely as biconditional connecting correct appreciation with intrinsic aesthetic value.

14 Dyck and Johnson, op.cit, pp. 280-281.

15 The Preference Requirement is similar in spirit to the analysis of value relations suggested by Wlodek Rabinowicz. See Rabinowicz, "Value Relations," Theoria, 74 (2008): 18-49. An interesting feature of Rabinowicz's framework is that it can accomodate non-standard value relations such as incomparability and parity.
} 
However, the Preference Requirement leads to a very similar puzzle as the one Dyck and Johnson discuss when we consider people who prefer inferior art. It is not uncommon that we prefer things which are, and which we hold to be, less aesthetically good than some other things. For example, a person who prefers J-Pop to classical music - that is, she appreciates J-Pop more than classical music-can still hold that classical music is aesthetically better than J-Pop. However, according to the Preference Requirement such a person would be making a mistake; if J-Pop is aesthetically worse than classical music, then it is impermissible to appreciate J-Pop more than classical music.

Here there seems to be a similar tension between the Preference Requirement and people's personal taste as the one highlighted by Dyck and Johnson's examples of bad art. In both cases we have examples of individuals whose aesthetic attitudes do not line up with aesthetic value, yet it is not clear that such a mismatch between attitudes and values is impermissible.

A straightforward solution to both puzzles is of course to say that these individuals are making a mistake: in both cases these individuals have attitudes which it is not correct to have. However, in so far as we think that this solution is not satisfactory with respect to bad art, perhaps because we find it implausible that to ascribe such a mistake to these otherwise aesthetically sensible individuals, then we should also not find it satisfactory with respect to preferring inferior art.

These two puzzles - appreciating bad art and preferring worse art-have in common that they challenge the Appreciation Requirement (and the Preference Requirement). Dyck and Johnson propose a solution to the puzzle of bad art by introducing a good aesthetic property which bad art can exemplify in virtue of being artistically bad. If successful, they would have shown that it is (sometimes) permitted to appreciate bad art without rejecting the Appreciation Requirement. However, their solution does not seem plausible as a solution to the second puzzle since the good making property they introduce presupposes that the work in question is artistically bad. However, in cases of preferring inferior art the two artworks need not be artistically bad; they can both be artistically good.

What this suggests is that there is a more general problem which both puzzles are instances of. The puzzle concerning bad art relies on there being a tight connection between aesthetic value and correct appreciation, roughly along the lines of the Appreciation Requirement. However, as I have argued, a similar puzzle arises once we consider a natural extension of the Appreciation Requirement: the Preference Requirement. It therefore seems that the problem of bad art, if there is one, concerns a more general question: to what extent ought a person's aesthetic attitudes track aesthetic value? ${ }^{16}$

Dyck and Johnson's solution can at best only partly address this problem. The way Dyck and Johnson aim to explain how it can be correct to appreciate bad art is by arguing for the existence of additional good making features which are typically had by bad works. However, this solution cannot plausibly be extended to

\footnotetext{
16 This puzzle has been dubbed "the problem of personal taste" by Levinson. See Nick Riggle, "Levinson on the Aesthetic Ideal," The Journal of Aesthetics and Art Criticism, 71 (2013): 277-281 for a critique of Levinson's characterization of the problem.
} 
the analogous puzzle regarding the correctness of aesthetically preferring worse art. A solution to both problems needs to address the thorny issue of how we ought to respond to aesthetic value in general.

Open Access This article is distributed under the terms of the Creative Commons Attribution 4.0 International License (http://creativecommons.org/licenses/by/4.0/), which permits unrestricted use, distribution, and reproduction in any medium, provided you give appropriate credit to the original author(s) and the source, provide a link to the Creative Commons license, and indicate if changes were made. 